\title{
PERFIL DO SUPORTE OFERECIDO PELAS INCUBADORAS BRASILEIRAS ÀS EMPRESAS INCUBADAS
}

\author{
Fabiano Maury Raupp \\ fabianoraupp@hotmail.com \\ Universidade do Estado de Santa Catarina - SC / Brasil \\ Ilse Maria Beuren \\ ilse@furb.br \\ Universidade Regional de Blumenau - SC / Brasil
}

Recebido em 22/12/2008

Aprovado em 23/03/2010

Disponibilizado em 01/08/2011

Avaliado pelo sistema double blind review

Revista Eletrônica de Administração

Editor: Luís Felipe Nascimento

ISSN 1413-2311 (versão on-line)

Editada pela Escola de Administração da Universidade Federal do Rio Grande do Sul.

Periodicidade: Quadrimestral

Sistema requerido: Adobe Acrobat Reader.

\section{INTRODUÇÃO}

A atual conjuntura exige um posicionamento tanto de micro e pequenas quanto de médias e grandes empresas. Em razão da formação de blocos econômicos e da virtualização dos mercados, os produtos passam a ser competitivos não apenas nacionalmente, mas também internacionalmente, o que exige um diferencial em relação aos produtos similares existentes no mercado.

Particularmente em relação às micro e pequenas empresas, estas nem sempre estão preparadas para os efeitos da globalização, haja vista que possuem uma estrutura organizacional mais simples, se comparadas às médias e grandes. Além disso, nem sempre são gerenciadas por pessoas com experiência e/ou formação para exercer essa função.

Para Fonseca e Kruglianskas (2000), as micro e pequenas empresas passaram a representar, no final do século 20, a maioria de unidades de negócio em todos os países do mundo, fossem industrializados, em desenvolvimento ou subdesenvolvidos. Estas passaram a 
responder por cerca de 50\%, quando não mais do valor da produção e a reter mais da metade do total dos postos de trabalho.

Observam ainda que, apesar de sua importância, este segmento apresenta um perfil de debilidades. Suas principais debilidades estruturais são: baixa intensidade de capital, capacidade de financiamento restrita, precariedade da função gerencial, baixa qualificação de recursos humanos, precariedade da função tecnológica, falta de planejamento a longo prazo, e pequeno poder de barganha com parceiros comerciais.

Um dos mecanismos utilizados para a redução dessas instabilidades é a instalação do empreendimento em incubadoras. As incubadoras procuram promover tal redução disponibilizando suportes administrativo, financeiro e de estrutura durante o processo de incubação.

Baêta (1999) afirma que os empreendimentos incubados estão melhor preparados quando se inserem no mercado de forma autônoma em virtude do uso compartilhado de serviços e instalações que, sem dúvida, diminuem o custo de desenvolvimento do negócio. Consolida-se, assim, uma cultura empresarial voltada para a cooperação, favorecendo a inovação tecnológica.

As incubadoras apresentam um importante papel socioeconômico já que conseguem, na maioria das vezes, reunir em um mesmo ambiente diversas facilidades, desde auxílio na obtenção de financiamentos até apoio administrativo e de estrutura. Assim, o presente artigo objetiva delinear o perfil do suporte oferecido pelas incubadoras brasileiras às empresas incubadas.

Para tanto, inicia-se fazendo uma incursão teórica nos fundamentos que sustentam o estudo, abordando as incubadoras, as fases do processo de incubação e o suporte das incubadoras às empresas incubadas. $\mathrm{Na}$ seqüência, identifica-se os procedimentos metodológicos. Em seguida, procede-se à descrição e análise dos dados coletados. Por último, apresenta-se as conclusões do estudo realizado, bem como recomendações para futuras pesquisas.

\section{INCUBADORAS DE EMPRESAS}

Incubadora é a denominação utilizada para definir o espaço institucional para apoiar a transformação de empresários potenciais em empresas crescentes e lucrativas (Lalkaka, 2003). Originalmente, a idéia de incubadoras esteve associada ao propósito de estimular o surgimento de negócios resultantes de projetos tecnológicos desenvolvidos em centros de 
Perfil do suporte oferecido pelas incubadoras brasileiras às empresas incubadas

pesquisa universitários ou não. A tipologia criada foi a tecnológica, voltada para apoiar o nascimento e o fortalecimento das chamadas empresas de base tecnológica (Fonseca e Kruglianskas, 2000).

Mais recentemente, a partir dos anos 90, as iniciativas diversificaram-se e ganharam espaço as incubadoras mistas, unidades criadas por governos locais com a finalidade de estimular o crescimento econômico e gerar empregos. Estas novas concepções tornaram-se mais abrangentes, incluindo o suporte fornecido às empresas que não fossem de base tecnológica.

As incubadoras de empresas constituem-se em um espaço no qual é disponibilizado às unidades de negócios, nelas instaladas, um conjunto de instrumentos e políticas que visam auxiliar o seu desenvolvimento. Medeiros (1998, p.6-7) salienta que:

no seu sentido original é um arranjo interinstitucional com instalações e infra-
estrutura apropriadas, estruturado para estimular e facilitar: a vinculação empresa-
universidade (e outras instituições acadêmicas); o fortalecimento das empresas e o
aumento de seu entrosamento; e o aumento da vinculação do setor produtivo com
diversas instituições de apoio (além das instituiçôes de pesquisa, prefeituras,
agências de fomento e financiamento - governamentais e privadas - instituições de
apoio às micro e pequenas empresas - como o Serviço Brasileiro de Apoio às
Micro e Pequenas Empresas no Brasil - e outras.

Aiub e Allegretti (1998, p.91) definem incubadora de empresas como um "empreendimento que visa abrigar empresas, oferecendo a elas espaço físico, infra-estrutura, recursos humanos e serviços especializados". Explicitam que, normalmente, variam de 300 a 1000 metros quadrados de área construída, onde podem ser abrigadas em torno de 10 empresas, em salas de 20 a 60 metros quadrados e infra-estrutura compartilhada.

Segundo a National Business Incubation Association - NBIA (http://www.nbia.org), a incubadora é um processo dinâmico de desenvolvimento de empresas de negócios. As incubadoras ajudam as novas empresas a sobreviver e crescer durante o período inicial em que são mais vulneráveis. Fornecem auxílio de gerência, financiamento e serviços de sustentação técnica. Oferece também serviços compartilhados de escritório, acesso a equipamentos, aluguéis e espaço flexíveis.

As incubadoras, conforme Hackett e Dilts (2004), são espaços compartilhados que proporcionam às novas empresas recursos tecnológicos e organizacionais; sistemas que criam valor agregado; monitoramento e ajuda empresarial, com o objetivo de facilitar o sucesso dos novos empreendimentos, reduzindo ou eliminando o custo de potenciais falhas que se apresentam na criação do negócio e que são controladas no período de incubação. Os novos empreendimentos recebem apoio do Governo, comunidades locais e investidores privados, 
com o intuito de superar determinadas dificuldades iniciais, tendo uma perspectiva de sucesso.

Para a Associação Nacional de Entidades Promotoras de Empreendimentos de Tecnologias Avançadas - ANPROTEC (http://www.anprotec.org.br/anprotec.htm\#5):

\begin{abstract}
uma incubadora é um ambiente flexível e encorajador onde é oferecida uma série de facilidades para o surgimento e crescimento de novos empreendimentos. Além da assessoria na gestão técnica e empresarial da empresa, a incubadora oferece a infra-estrutura e serviços compartilhados necessários para o desenvolvimento do novo negócio, como espaço físico, salas de reunião, telefone, fax, acesso à Internet, suporte em informática, entre outros. Desta forma, as incubadoras de empresas geridas por órgãos governamentais, universidades, associações empresariais e fundações, são catalizadoras do processo de desenvolvimento e consolidação de empreendimentos inovadores no mercado competitivo.
\end{abstract}

Sobre as características, Baêta (1999) enuncia que as incubadoras implicam em condições bastante específicas e não se esgotam numa simples criação de empresas, mas também o monitoramento para estimular o processo de inovação. Assim, promovem oportunidades para o desenvolvimento tecnológico do processo produtivo e oferecem aos novos empreendedores, além de espaço físico e os serviços de escritório, o apoio administrativo, aconselhamento e consultoria gerencial e de marketing.

Amato Neto (2000) afirma que a missão é a de fornecer serviços e recursos, em termos de profissionais competentes, instalações adequadas e infra-estrutura administrativa e operacional à disposição das empresas. Criam um ambiente favorável à consolidação de novos empreendimentos por meio de algumas iniciativas, como: fornecimento de apoio técnico e gerencial às empresas, promoção e aceleração da consolidação de empresas, estimulação do espírito empreendedor, desenvolvimento de ações associativas e compartilhadas, redução dos custos para o conjunto das empresas e seus parceiros, busca de novos apoios e parcerias para as empresas, divulgação das empresas e seus produtos e participação de outras redes.

A partir da infra-estrutura disponibilizada, o desenvolvimento dos empreendimentos concebidos é facilitado, haja vista o apoio técnico, administrativo e operacional oferecido. Estas facilidades reduzem a instabilidade vivida pelas micro e pequenas empresas e proporcionam muitas perspectivas à medida que saem da incubadora e atuam sozinhas no mercado.

\footnotetext{
As incubadoras devem funcionar como empresas de prestação de serviços que, através de parcerias e esforços compartilhados, colocam competências, instalações e infra-estrutura administrativa e operacional à disposição das empresas abrigadas, criando ambiente favorável ao surgimento e à consolidação de empreendimentos modernos e competitivos (Medeiros, 1998, p.7).
} 
Perfil do suporte oferecido pelas incubadoras brasileiras às empresas incubadas

O principal objetivo deve ser a produção de empresas de sucesso, em constante desenvolvimento, financeiramente viáveis e competitivas em seu mercado, mesmo após deixarem a incubadora, geralmente em um prazo de três a quatro anos. Os empreendedores passam por um processo de seleção para serem admitidos em uma incubadora, devendo apresentar, entre outros elementos, um plano de negócios de seu empreendimento (Dornelas, 2001).

Medeiros e Atas (1995) lembram que a redução destes tipos de problemas poderá ser obtida mediante o atendimento de alguns requisitos antes mesmo que a incubadora seja constituída. Os requisitos que precedem a instalação dividem-se em requisitos mínimos, recomendáveis e desejáveis. No Quadro 1 apresentam-se os requisitos para a instalação de uma incubadora.

\begin{tabular}{|l|l|}
\hline & $\begin{array}{l}\text { - existência de empreendedores interessados; } \\
\text { - viabilidade técnica e comercial das propostas; }\end{array}$ \\
\hline & - parceiros comprometidos com o empreendimento; \\
- apoio político e disponibilidade de laboratórios e de recursos humanos.
\end{tabular}

Quadro 1: Requisitos para a constituição de uma incubadora

Fonte: Adaptado de Medeiros e Atas (1995).

As incubadoras de empresas podem ser caracterizadas como organizações estruturadas e destinadas ao nascimento, crescimento e desenvolvimento de micro e pequenas empresas por meio de uma infra-estruturada administrativa, física, operacional e financeira, colocada à disposição dos empreendedores. Neste ambiente prima-se pela iniciativa, inovação e, sobretudo, uma constante aprendizagem.

\section{FASES DO PROCESSO DE INCUBAÇÃO}

O processo de incubação corresponde ao período no qual a empresa permanece incubada. Moreira (2002, p.60) expõe que "durante este tempo a empresa é acompanhada pela equipe da incubadora que trabalha para organizá-la gerencialmente e com isso melhorar suas chances de sucesso e permanência no mercado". 
O período em que a empresa permanece incubada é dividido em fases, cada qual com características e funcionalidades distintas. Entretanto, dependendo da literatura consultada, o número de fases, bem como suas denominações, poderão variar. No Quadro 2 apresenta-se as fases do processo de incubação preconizadas por diferentes autores.

\begin{tabular}{|c|l|}
\hline \multicolumn{1}{|c|}{ Autor } & \multicolumn{1}{c|}{ Fases do processo de incubação } \\
\hline & - Implantação \\
\hline \multirow{3}{*}{ Medeiros e Atas (1995) } & - Crescimento \\
& - Consolidação \\
& - Maturação \\
\hline \multirow{3}{*}{ Moreira (2002) } & - Seleção \\
& - Incubação \\
& - Desenvolvimento \\
& - Crescimento \\
\hline \multirow{3}{*}{ Russi Junior (1999) } & - Instaçação \\
\hline & - Lançamento início das operações \\
& - Crescimento produto \\
& - Amadurecimento \\
& - Consolidação e desligamento do programa \\
\hline
\end{tabular}

Quadro 2: Fases do processo de incubação preconizadas por diferentes autores

Fonte: Elaborado pelo autor.

Enquanto Medeiros e Atas (1995) apresentam quatro fases de um processo de incubação, Moreira (2002) apresenta cinco, acrescentando a fase de seleção. Num comparativo, as demais fases, apesar de terem denominações diferentes, contemplam em algumas delas características equivalentes. Já Russi Junior (1999) identifica uma fase específica para o lançamento do produto, sendo que nas demais fases encontra-se similaridades em relação às fases preconizadas pelos autores já apresentados. Embora sejam constatadas algumas diferenças nas fases que compõem o processo de incubação, neste trabalho optou-se por detalhar as fases apresentadas por Moreira (2002), haja vista que contempla, de maneira geral, as fases apresentadas pelos outros autores abordados.

\section{a) Fase de seleção}

A seleção do empreendimento a ser instalado em uma incubadora consiste na primeira fase do processo de incubação. Nesta fase é comum a incubadora solicitar um plano de negócios ao candidato para que seja possível analisar sua proposta de incubação da empresa. Boa parte das incubadoras exige que o candidato participe de um curso rápido (cerca de 20 horas) sobre gestão de pequenos negócios e elaboração de plano de negócios (Moreia, 2002).

Para que obtenha sucesso nesta fase, a empresa deverá preparar-se atendendo a todos os requisitos exigidos pela incubadora. A viabilização da empresa no processo de incubação depende da seleção e aprovação pela incubadora nesta fase. 


\section{b) Fase de incubação}

A fase de incubação é considerada uma fase intermediária entre a seleção e o seu desenvolvimento. Esta fase corresponde, basicamente, às formalizações de incubação e instalação da empresa na incubadora.

$\mathrm{Na}$ incubação, conforme Moreira (2002), o plano de negócios pré-aprovado é encaminhado ao conselho da instituição a fim de receber aprovação final. Em caso de aprovação, o processo segue para a contratação formal. Em de reprovação, o conselho pode apontar os pontos críticos e solicitar a correção dos mesmos como um condicionante para a sua aprovação. Esta fase resume-se em avaliar as necessidades de infra-estrutura, apresentação dos termos do contrato, apresentação das regras e normas da incubadora, assinatura do contrato e instalação da empresa.

\section{c) Fase de desenvolvimento}

A terceira fase de um processo de incubação pode ser denominada fase de desenvolvimento. Nesta fase a empresa incubada começa a desenvolver suas estratégias comerciais, planejar suas atividades, controlar seus recursos, dentre outros fatores.

O processo de desenvolvimento do empreendimento talvez seja o mais desafiador para a equipe da incubadora e, é claro, para o próprio empresário. A maior parte das atenções e dos recursos está destinada ao desenvolvimento do produto, envolvendo testes e confecção do protótipo. Porém, problemas relacionados a atrasos nos programas de desenvolvimento, problemas com a equipe, falta de recursos e falta de controle por parte do empresário costumam ser a regra durante esta fase (Moreira, 2002).

\section{d) Fase de crescimento}

A fase de crescimento representa a expansão dos elementos definidos na fase anterior. Na fase de crescimento, segundo Moreira (2002), a empresa deverá buscar a expansão comercial, conquistando novas fatias de mercado ou novos mercados consumidores. Quando a incubadora é solicitada a participar de uma solução de demanda, freqüentemente são questões de relevância para a empresa, envolvendo questões mais específicas relacionadas à conquista de importantes clientes e mercados situados em outras regiões ou estados.

Esta fase poderá ter uma duração consideravelmente maior que as fases anteriores, em função daquilo que se pretende empreender na mesma. Nesta fase, grande parte dos empreendedores já apresentam características que os enquadram como gestores capazes de 
administrar sozinhos a empresa.

e) Fase de liberação

A quinta e última fase é denominada fase de liberação. Como uma consequiência positiva do processo de incubação, na fase de liberação a empresa já está pronta para sair da incubadora, seu faturamento já atingiu um nível que a permite migrar para uma nova sede física. A incubadora não consegue mais acomodar a empresa, e sua expansão dentro passa a ser um ponto crítico dado a limitação de espaço para novas empresas candidatas a incubação (Moreira, 2002).

A fase de liberação representa o desligamento da empresa incubada em relação à incubadora. Diante do crescimento e desenvolvimento adquirido nas fases anteriores, a empresa incubada mostra-se capaz de sobreviver e atuar sozinha no mercado.

\section{SUPORTE DAS INCUBADORAS ÀS EMPRESAS INCUBADAS}

Rice e Mattews (1995) entendem que o foco nos serviços e nos recursos, para resolução dos problemas das empresas incubadas e o desenvolvimento de serviços para o atendimento das necessidades específicas compreendem fatores críticos de sucesso para as incubadoras. Observa-se que a questão da percepção das diferenças dos projetos é particularmente importante para a avaliação e para o desenvolvimento das incubadoras. Nesse sentido, a eficácia e a eficiência dos serviços de apoio oferecidos dependeriam do reconhecimento das especificidades das necessidades da empresas incubadas.

Barrow (2001) afirma que o sucesso de uma incubadora decorre da combinação de sete componentes: objetivos claros, perfil do coordenador da incubadora, disponibilização de serviços, recursos compartilhados, espaço físico, acesso a financiamentos e seleção dos projetos.

Conforme Baêta (1999), são vários os serviços oferecidos pelas incubadoras brasileiras às empresas incubadas: espaço físico; serviços de escritório; orientação na elaboração do plano de negócio; identificação de parceiros competentes; apoio à busca de financiamento; acesso a laboratórios e informações científico-tecnológicas; participação em cursos de atualização e treinamento; e participação em feiras e congressos.

Medeiros (1998) agrupa os serviços oferecidos pelas incubadoras em quatro categorias. Ressalta que, para cumprir sua missão, as incubadoras necessitam reunir quatro 
Perfil do suporte oferecido pelas incubadoras brasileiras às empresas incubadas

ingredientes indissociáveis: instalações; infra-estrutura física, administrativa e operacional; recursos humanos; e serviços especializados.

Cabe lembrar que os serviços oferecidos podem variar de incubadora para incubadora. Diferentes autores apresentam agrupamentos diversos para os serviços. Para este estudo, convencionou-se separar os serviços que compõem o suporte fornecido pelas incubadoras em cinco categorias: suporte administrativo, suporte financeiro, suporte de estrutura, suporte por meio de programas desenvolvidos pelas incubadoras, e suporte por meio de programas de agentes de desenvolvimento junto às incubadoras.

\subsection{Suporte administrativo}

Segundo Medeiros e Atas (1995), a infra-estrutura disponível nas incubadoras decompõe-se em dois tipos: infra-estrutura física e administrativa; e serviços especializados. Contudo, o que os autores citam como serviços especializados parece enquadrar-se como suporte administrativo de acordo com as tipologias propostas por este estudo.

A partir de adaptações feitas aos autores, podem ser citados como serviços que fazem parte do suporte administrativo: gestão tecnológica e empresarial; informações mercadológicas; orientação jurídica; serviços de contabilidade; registro e legalização da empresa; compra conjunta de materiais e equipamentos; divulgação e marketing; contratação de assessorias; elaboração de documentos técnicos e empréstimos de equipamentos; cadastramento e homologação em órgãos governamentais; e registro de marcas e patentes.

Todos os serviços destacados, sem exceção, são importantes para uma gestão empresarial eficiente e eficaz. Trata-se de elementos que irão consubstanciar o processo decisório do novo empreendimento.

\subsection{Suporte financeiro}

O suporte financeiro compreende o apoio desde a captação até a aplicação dos recursos. Dentre os elementos que compõem o suporte financeiro podem ser observados: captação de recursos; aplicação dos recursos; apoio na busca de capital de risco; juros subsidiados; e custos compartilhados.

Medeiros (1998) afirma que, em relação à existência de recursos financeiros para a montagem e o funcionamento das incubadoras, o Brasil dispõe de mecanismo importante que constitui uma espécie de capital semente. Podem ser citados como exemplos as bolsas 
concedidas pelo Programa de Capacitação de Recursos Humanos para Atividades Estratégicas (RHAE) do Ministério da Ciência e Tecnologia.

Complementa que as instituições de ensino e pesquisa, os governos estaduais, as prefeituras e mesmo diversas entidades privadas, como a Federação das Indústrias do Estado de São Paulo (FIESP), tem aportado recursos para as incubadoras brasileiras. Há também o estímulo do sistema SEBRAE que tem sido significativo. Com a participação financeira dos interessados e de organismos de fomento e financiamento, existem linhas de apoio especialmente estruturadas para dar suporte às entidades gestoras das incubadoras e às empresas, especialmente os apoios na forma de consultorias e treinamentos.

O suporte financeiro é um elemento fundamental, principalmente em decorrência do atual cenário econômico. As incubadoras buscam junto à diversas instituições, públicas ou privadas, recursos financeiros para o desenvolvimento destes empreendimentos.

\subsection{Suporte de estrutura}

Segundo Medeiros e Atas (1995), a infra-estrutura física da incubadora compreende: prédios com módulos de uso individual; hall de entrada e show room; áreas comuns como recepção, secretaria, salas de reunião, de serviços de apoio e treinamento; serviços de secretaria, datilografia e mensageiros; serviços de comunicação como fax, telefone e correio; serviços de limpeza e segurança (portaria e vigilância); e almoxarifado, vestuário, sanitários e copa. Além deste conjunto, citam alguns serviços especializados, que parecem dizer respeito ao suporte de estrutura, como: uso de laboratórios das universidades e centros de pesquisa; e informações em livros e acesso a base de dados.

Conforme relata Medeiros (1998), a incubadora normalmente aproveita prédios já existentes. A título de exemplo, em uma área de $1.200 \mathrm{~m}^{2}$ podem ser abrigadas até dez empresas que repartem entre si os custos de locação e da infra-estrutura física, administrativa e operacional. Serviços de uso exclusivo de cada empresa são pagos, em separado, para que possam utilizar essas facilidades.

Medeiros (1998, p.9) cita uma pesquisa realizada para o Programa das Nações Unidas para o Desenvolvimento (PNUD), na qual foi constatado que no Brasil "há dificuldades pontuais que não combinam com a agilidade exigida pelos negócios, como infra-estrutura física não dimensionada de forma adequada e equipe de apoio administrativo mal preparada". Enfatiza ainda que "houve casos em que prédios foram reformados à toa, pois ocorreu mudança na orientação da instituição responsável pelo empreendimento. Em decorrência, os 
Perfil do suporte oferecido pelas incubadoras brasileiras às empresas incubadas

módulos ficaram subutilizados ou inabitados, num lamentável exemplo de desperdício de verbas".

\subsection{Suporte por meio de programas desenvolvidos pelas incubadoras}

As incubadoras de empresas desenvolvem vários programas com o objetivo de instrumentalizar o empreendedor para a gestão técnica, operacional e administrativa do negócio. Baêta (1999) destaca que as modalidades de transferência de tecnologia por meio de incubadoras mais significativas são as que evidenciam o fluxo de informações e conhecimentos entre as empresas e a comunidade acadêmica.

A autora cita as seguintes modalidades: utilização de laboratórios universitários pelas empresas; utilização de bibliotecas e instalações nas universidades ou dos centros de P\&D; contratação de consultores universitários para as empresas, mediante bolsas e outras modalidades; intermediação da incubadora em contratos de pesquisa entre empresas e universidade; participação de pesquisadores e alunos universitários nas incubadoras; participação dos empresários em cursos de atualização e reciclagem nas universidades; participação dos empresários em congressos acadêmicos; realização de seminários acadêmicos sobre o tema incubadoras e parques tecnológicos.

Além das perspectivas citadas, há também programas de agentes de desenvolvimento junto às incubadoras. Alguns órgãos do governo e outras instituições têm disponibilizado desde financiamentos até a capacitação por meio de consultorias e treinamentos.

\subsection{Suporte por meio de programas de agentes de desenvolvimento junto às incubadoras}

Os principais programas de agentes de desenvolvimento junto às incubadoras são: Programa Nacional de Apoio à Incubadoras de Empresas, Projeto Inovar, Programa de Capacitação de Recursos Humanos para Atividades Estratégicas, Programa SOFTEX, SEBRAEtec, Programa de Apoio Tecnológico às Micro e Pequenas Empresas, Programa de Capacitação Tecnológica, e Programa Brasil Empreendedor.

Fundamentados principalmente no aporte financeiro, tais programas ajudam também a expandir os serviços administrativos e de estrutura das incubadoras às empresas incubadas. Todavia, é importante analisar esses aspectos por meio de pesquisa empírica. Considerando-se que o foco da pesquisa é identificar o suporte que as incubadoras brasileiras oferecem às empresas incubadas, apresenta-se os procedimentos metodológicos utilizados para a execução 
do estudo.

\section{PROCEDIMENTOS METODOLÓGICOS}

No tocante à tipologia relacionada aos objetivos, esta pesquisa consiste de um estudo do tipo descritivo. De acordo com Gil (1999), a pesquisa descritiva tem como principal objetivo descrever características de determinada população ou fenômeno ou o estabelecimento de relações entre as variáveis. Uma de suas características mais significativas está na utilização de técnicas padronizadas de coleta de dados.

No que concerne aos procedimentos, refere-se a uma pesquisa do tipo levantamento ou survey. Tripodi, Fellin e Meyer (1981, p.39) mencionam que "pesquisas que procuram descrever algumas características de populações designadas são tipicamente representadas por estudos de survey". Os dados referentes a este tipo de pesquisa podem ser coletados como base em uma amostra retirada de uma determinada população ou universo que se deseja conhecer.

A perspectiva do estudo é de corte transversal ou seccional, pois os dados foram coletados em um determinado ponto no tempo, tendo por base uma amostra selecionada para descrever as características da população num momento definido. Richardson (1999) explica que no corte transversal identifica-se a população, escolhe-se a amostra e realiza-se a pesquisa.

Quanto à abordagem do problema, o estudo utilizou-se da abordagem quantiqualitativa. Richardson (1999) diferencia o método qualitativo do quantitativo à medida que aquele não emprega instrumentos estatísticos como base no processo de análise de um problema, não há intenção de numerar ou medir unidades ou categorias homogêneas.

O objeto de análise do estudo é organizacional, contemplando uma população de 179 incubadoras de empresas brasileiras. Para tal, consultou-se uma relação disponibilizada pela equipe de pesquisa da ANPROTEC, no site da referida associação (http://www.anprotec.org.br). Nesta constavam 184 incubadoras, mas 1 estava em duplicidade e 4 já tinham encerrado suas atividades, totalizando 179 incubadoras ativas.

Devido a impossibilidade de analisar todas as incubadoras optou-se por selecionar uma amostra. Assim, adotou-se o conceito de amostragem, considerando como amostra o retorno dos questionários respondidos de 37 incubadoras brasileiras.

Desse modo, o método adotado para a seleção da amostra constitui-se como sendo do tipo não-probabilístico. Martins (2000) explicita que a amostragem não-probabilística ocorre 
Perfil do suporte oferecido pelas incubadoras brasileiras às empresas incubadas

quando há uma escolha deliberada dos elementos da amostra.

Em meio aos tipos de amostragens não-probabilísticas, utilizou-se a amostragem por acessibilidade ou conveniência. Na amostragem por acessibilidade, segundo Gil (1999), o pesquisador obtém os elementos a que tem maior facilidade de acesso, admitindo que eles possam efetivamente representar de forma adequada a população. Na Tabela 1 apresenta-se a relação das incubadores brasileiras que compuseram a amostra da pesquisa.

Tabela 1: Relação das incubadores brasileiras que compuseram a amostra da pesquisa

\begin{tabular}{|c|c|c|c|}
\hline n. ${ }^{\circ}$ & Incubadora & Cidade & UF \\
\hline 1 & $\begin{array}{l}\text { Núcleo de Incubação de Negócios Sócio-Cultural da Universidade Federal de } \\
\text { Alagoas }\end{array}$ & Xingó & AL \\
\hline 2 & Condomínio de Empreendedores e de Inovação Tecnológica - COMPETE & Salvador & BA \\
\hline 3 & Incubadora de Empresas do CDT/UnB & Brasília & DF \\
\hline 4 & Fundação Educacional de Patos de Minas - IEP & Patos de Minas & MG \\
\hline 5 & $\begin{array}{l}\text { Incubadora de Base Tecnológica de Automação Industrial e Instrumentação } \\
\text { Médica de Belo Horizonte - ITAIM }\end{array}$ & Belo Horizonte & MG \\
\hline 6 & Incubadora de Empresas do Inatel & Santa Rita do Sapucaí & MG \\
\hline 7 & Incubadora de Empresas de Base Gerencial da UNAMA & Belém & PA \\
\hline 8 & $\begin{array}{l}\text { Incubadora de Empresas de Base Tecnológica do Estado de Pernambuco - ITEP } \\
\text { - INCUBATEP }\end{array}$ & Recife & $\mathrm{PE}$ \\
\hline 9 & Fundação Educare de Campo Mourão & Campo Mourão & PR \\
\hline 10 & Incubadora Tecnológica de Curitiba - INTEC & Curitiba & PR \\
\hline 11 & Incubadora Gênesis de Pato Branco & Pato Branco & PR \\
\hline 12 & $\begin{array}{l}\text { Núcleo de Empreendedorismo e Projetos Multidisciplinares da Universidade } \\
\text { Federal do Paraná - NEMPS }\end{array}$ & Curitiba & PR \\
\hline 13 & Incubadora Internacional de Empresas de Software & Curitiba & PR \\
\hline 14 & Incubadora de Empresas de Base Tecnológica da UFF & Niterói & RJ \\
\hline 15 & Incubadora de Empresas do Inmetro & Duque de Caxias & RJ \\
\hline 16 & Fundação Bio-Rio & Rio de Janeiro & RJ \\
\hline 17 & Núcleo de Incubação Tecnológica do CEFET/RN & Natal & RN \\
\hline 18 & $\begin{array}{l}\text { Centro de Emprendimento do Instituto de Informática da UFRGS - CEI/II - } \\
\text { UFRGS }\end{array}$ & Porto Alegre & $\mathrm{RS}$ \\
\hline 19 & Sociedade Incubadora Tecnológica de Caxias do Sul - ITEC & Caxias do Sul & $\mathrm{RS}$ \\
\hline 20 & Unidade de Desenvolvimento Tecnológico da Unisinos - UNITEC & São Leopoldo & $\mathrm{RS}$ \\
\hline 21 & Incubadora de Passo do Sobrado & Passo do Sobrado & $\mathrm{RS}$ \\
\hline 22 & Berçário Industrial & Torres & $\mathrm{RS}$ \\
\hline 23 & Incubadora de Empresas de Caiçara & Caiçara & $\mathrm{RS}$ \\
\hline 24 & Incubadora Empresarial de Dom Pedrito & Dom Pedrito & $\mathrm{RS}$ \\
\hline 25 & Blumenau Pólo de Software- BLUSOFT & Blumenau & $\mathrm{SC}$ \\
\hline 26 & Microdistrito Industrial de Base Tecnológica - MIDI TECNOLÓGICO & Florianópolis & $\mathrm{SC}$ \\
\hline 27 & Incubadora de Base Tecnológica de Joinville - MIDIville & Joinville & $\mathrm{SC}$ \\
\hline 28 & Centro Empresarial para Laboração de Tecnologias Avançadas - CELTA & Florianópolis & $\mathrm{SC}$ \\
\hline 29 & Fundação Softville & Joinville & $\mathrm{SC}$ \\
\hline 30 & Incubadora de empresas de base tecnológica da UNICAMP - INCAMP & Campinas & SP \\
\hline 31 & Agência de Desenvolvimento Econômico de Bebedouro & Bebedouro & SP \\
\hline 32 & Incubadora de Empresas de Jardinópolis & Jardinópolis & SP \\
\hline 33 & Incubadora de Birigui & Birigui & $\mathrm{SP}$ \\
\hline 34 & Incubadora de Empresas de Limeira & Limeira & SP \\
\hline 35 & Incubadora de Empresas de Botucatu & Botucatu & SP \\
\hline 36 & Núcleo de Desenvolvimento Empresarial Pedro Khuri Sakr & Penápolis & SP \\
\hline 37 & Núcleo de Desenvolvimento Empresarial Incubadora de Bariri & Bariri & SP \\
\hline
\end{tabular}

Fonte: Dados da pesquisa. 
Fabiano Maury Raupp \& Ilse Maria Beuren

Para a coleta de dados foi utilizada a técnica de questionários, com perguntas abertas e fechadas, enviados por correio eletrônico e aplicados aos coordenadores das incubadoras. A análise dos dados coletados deu-se por meio da abordagem quanti-qualitativa. Para tanto, foram utilizadas as técnicas de análise de conteúdo e descritiva. Bardin (1979 apud Richardson, 1999) explicita que a análise de conteúdo é um conjunto de técnicas de análise das comunicações visando obter, através de procedimentos sistemáticos e objetivos de descrição de conteúdo das mensagens, indicadores (quantitativos ou não) que permitam inferir conhecimentos relativos às condições de produção dessas mensagens.

Por sua vez, em relação à análise descritiva, Contandriopoulos et al. (1994) diz que é utilizada para relatar o comportamento de uma variável em uma população ou no interior de uma subpopulação, utilizando para a análise dos dados os instrumentos disponibilizados pela estatística.

\section{DESCRIÇÃO E ANÁLISE DOS DADOS COLETADOS}

Inicia-se a descrição e análise dos dados caracterizando as incubadoras brasileiras. Em seguida, contempla-se os requisitos necessários para a instalação de empreendimentos nestas incubadoras e o suporte oferecido às empresas incubadas nas diferentes fases do processo de incubação.

\subsection{Caracterização das incubadoras brasileiras pesquisadas}

A caracterização das incubadoras brasileiras tem como aspectos investigados: localização das incubadoras, ramo de atuação das incubadoras e estágio de desenvolvimento das empresas incubadas.

\subsubsection{Localização das incubadoras}

As incubadoras de empresas brasileiras estão localizadas em quase todos os Estados brasileiros: Alagoas, Amapá, Amazonas, Bahia, Ceará, Distrito Federal, Espírito Santo, Goiás, Mato Grosso do Sul, Minas Gerais, Pará, Paraíba, Paraná, Pernambuco, Piauí, Rio Grande do Sul, Rio Grande do Norte, Rio de Janeiro, Santa Catarina e São Paulo. A distribuição, por Estado, das incubadoras brasileiras e das incubadoras estudadas é apresentada na Tabela 2 . 
Perfil do suporte oferecido pelas incubadoras brasileiras às empresas incubadas

Tabela 2: Dstribuição das incubadoras por Estado

\begin{tabular}{|c|c|c|c|c|}
\hline \multirow{2}{*}{ Estado } & \multicolumn{2}{|c|}{ População } & \multicolumn{2}{|c|}{ Amostra } \\
\hline & n. $^{\circ}$ & $\%$ & n. ${ }^{\circ}$ & $\%$ \\
\hline Alagoas & 5 & 2,79 & 1 & 2,70 \\
\hline Amapá & 1 & 0,56 & 0 & 0,00 \\
\hline Amazonas & 1 & 0,56 & 0 & 0,00 \\
\hline Bahia & 6 & 3,35 & 1 & 2,70 \\
\hline Ceará & 3 & 1,68 & 0 & 0,00 \\
\hline Distrito Federal & 2 & 1,12 & 1 & 2,70 \\
\hline Espírito Santo & 1 & 0,56 & 0 & 0,00 \\
\hline Goiás & 1 & 0,56 & 0 & 0,00 \\
\hline Mato Grosso do Sul & 4 & 2,23 & 0 & 0,00 \\
\hline Minas Gerais & 16 & 8,94 & 3 & 8,11 \\
\hline Pará & 4 & 2,23 & 1 & 2,70 \\
\hline Paraíba & 1 & 0,56 & 0 & 0,00 \\
\hline Paraná & 12 & 6,70 & 5 & 13,51 \\
\hline Pernambuco & 5 & 2,79 & 1 & 2,70 \\
\hline Piauí & 1 & 0,56 & 0 & 0,00 \\
\hline Rio de Janeiro & 10 & 5,59 & 3 & 8,11 \\
\hline Rio Grande do Norte & 2 & 1,12 & 1 & 2,70 \\
\hline Rio Grande do Sul & 60 & 33,52 & 7 & 18,92 \\
\hline Santa Catarina & 11 & 6,15 & 5 & 13,51 \\
\hline São Paulo & 33 & 18,44 & 8 & 21,62 \\
\hline Total & 179 & 100 & 37 & 100 \\
\hline
\end{tabular}

Fonte: Dados da pesquisa.

Observa-se uma maior concentração de incubadoras no Estado do Rio Grande do Sul, com 60 incubadoras, seguido do Estado de São Paulo com 33, Minas Gerais com 16, Paraná com 12, Santa Catarina com 11 e Rio de Janeiro com 10. As demais incubadoras encontramse distribuídas em outros Estados, mas com menor representação numérica. Há várias razões que podem explicar esta distribuição: nível de industrialização do Estado, comprometimento do Estado com o desenvolvimento econômico da região, interesse no incremento tecnológico, busca pela competitividade das empresas do Estado no âmbito nacional e/ou internacional.

Quanto às incubadoras objeto de estudo, os números mais representativos por Estado equivalem ao ranking da população, porém com uma diferença na ordem de disposição. Os Estados por ordem decrescente em número de incubadoras estudadas são: São Paulo com 8; Rio Grande do Sul com 7; Santa Catarina e Paraná, cada um com 5; Minas Gerais e Rio de Janeiro, cada um com 3.

Com base na distribuição por Estado fez-se também a distribuição das incubadoras por região brasileira, sendo elas: Norte, Nordeste, Centro-Oeste, Sudeste e Sul. A localização das incubadoras por região é demonstrada na Tabela 3. 
Fabiano Maury Raupp \& Ilse Maria Beuren

Tabela 3: Localização das incubadoras por região brasileira

\begin{tabular}{l|c|c|c|c}
\multirow{2}{*}{ Região } & \multicolumn{2}{c|}{ População } & \multicolumn{2}{c}{ Amostra } \\
\cline { 2 - 5 } Norte & n. ${ }^{{ }^{*}}$ & $\%$ & n. $^{{ }^{\circ}}$ & $\%$ \\
\hline Nordeste & 6 & 3,35 & 1 & 2,70 \\
\hline Centro-Oeste & 23 & 12,85 & 4 & 10,81 \\
\hline Sudeste & 7 & 3,91 & 1 & 2,70 \\
\hline Sul & 60 & 33,52 & 14 & 37,84 \\
\hline TOTAL & 83 & 46,37 & 17 & 45,95 \\
\hline
\end{tabular}

Fonte: Dados da pesquisa.

Como consequiência da concentração de incubadoras nos Estados já mencionados, as regiões com maior representatividade em número de incubadoras são a Região Sul com 83 e a Região Sudeste com 60. Apresentam números menores a Região Nordeste com 23, CentroOeste com 7, e Norte com 6.

No que concerne à amostra da pesquisa, a Região Sul apresenta o maior número com 17 incubadoras; na seqüência tem-se a Região Sudeste com 14, a Nordeste com 4, e a Região Norte e Centro-Oeste, com 1 cada. Embora se tenha adotado uma amostra não-probabilística, observa-se uma certa aderência nas estratificações por regiões, em se comparando a população com a amostra selecionada.

\subsubsection{Ramo de atuação das incubadoras}

As tipologias de incubadoras mais comuns no Brasil, conforme dados levantados na pesquisa, são incubadoras de empresas de base tecnológica, incubadoras de empresas de setores tradicionais e incubadoras mistas. Atualmente estão surgindo outros tipos de incubadoras, conforme necessidades específicas de cada região, como: agroindustrial, cultural, artes, cooperativa, setorial, social e virtual. Na Tabela 4 demonstra-se os números de cada tipologia de incubadora, por região.

Tabela 4: Ramo de atuação das incubadoras estudadas por região brasileira

\begin{tabular}{|c|c|c|c|c|c|c|}
\hline \multirow{3}{*}{ Região } & \multicolumn{6}{|c|}{ Tipologia de incubadora } \\
\hline & \multicolumn{2}{|c|}{ Base tecnológica } & \multicolumn{2}{|c|}{ Tradicional } & \multicolumn{2}{|c|}{ Mista } \\
\hline & $\mathrm{n.}^{\mathrm{o}}$ & $\%$ & $\mathrm{n}^{\circ}$ & $\%$ & $\mathrm{n}^{\mathrm{o}}$ & $\%$ \\
\hline Norte & 0 & 0,00 & 0 & 0,00 & 1 & 20,00 \\
\hline Nordeste & 3 & 13,64 & 1 & 10,00 & 0 & 0,00 \\
\hline Centro-Oeste & 1 & 4,55 & 0 & 0,00 & 0 & 0,00 \\
\hline Sudeste & 6 & 27,27 & 5 & 50,00 & 3 & 60,00 \\
\hline Sul & 12 & 54,55 & 4 & 40,00 & 1 & 20,00 \\
\hline TOTAL & 22 & 100 & 10 & 100 & 5 & 100 \\
\hline
\end{tabular}

Fonte: Dados da pesquisa.

A tipologia que apresenta maior número é a de base tecnológica com 22 incubadoras. 
Perfil do suporte oferecido pelas incubadoras brasileiras às empresas incubadas

Estas estão assim distribuídas, 54,55\% na Região Sul, 27,27\% na Região Sudeste, 13,64\% na Região Nordeste e 4,55\% na Região Centro-Oeste.

As incubadoras tradicionais, em número de 10, estão localizadas na Região Sudeste e Sul, com 5 e 4 respectivamente, e 1 na Região Nordeste. Entre as incubadoras mistas, 3 estão localizadas na Região Sudeste, 1 na Região Sul e 1 na Região Norte.

\subsubsection{Estágio de desenvolvimento das empresas incubadas}

Para inferir sobre o atual estágio de desenvolvimento das empresas incubadas nas incubadoras brasileiras, optou-se por detalhar as fases apresentadas por Moreira (2002), haja vista que contempla, de maneira geral, as fases apresentadas pelos outros autores abordados na revisão bibliográfica. A Tabela 5 demonstra a quantidade de empresas em cada fase do processo de incubação.

Tabela 5: Estágio de desenvolvimento das empresas incubadas

\begin{tabular}{l|c|c|c|c|c|c}
\hline \multirow{2}{*}{ Fases do processo de incubação } & \multicolumn{9}{|c}{ Tipologia de incubadora } \\
\cline { 2 - 7 } & \multicolumn{2}{|c|}{ Base tecnológica } & \multicolumn{2}{|c}{ Tradicional } & \multicolumn{2}{c}{ Mista } \\
\cline { 2 - 7 } & $\mathrm{n}^{{ }^{\circ}}$ & $\%$ & $\mathrm{n}^{{ }^{\circ}}$ & $\%$ & n. $^{{ }^{\circ}}$ & $\%$ \\
\hline Seleção & 7 & 2,72 & 12 & 17,39 & 19 & 21,35 \\
\hline Implantação & 43 & 16,73 & 11 & 15,94 & 21 & 23,60 \\
\hline Desenvolvimento & 65 & 25,29 & 19 & 27,54 & 11 & 12,36 \\
\hline Crescimento & 113 & 43,97 & 17 & 24,64 & 35 & 39,33 \\
\hline Liberação & 29 & 11,28 & 10 & 14,49 & 3 & 3,37 \\
\hline TOTAL & 257 & 100 & 69 & 100 & 89 & 100 \\
\hline
\end{tabular}

Fonte: Dados da pesquisa.

As incubadoras pesquisadas, em conjunto, abrigam 415 empresas. Entre as empresas incubadas, 257 são de base tecnológica, 69 tradicionais e 89 mistas. Das 415 empresas incubadas, observa-se que 165 estão na fase de crescimento, bastando apenas passar pela fase de liberação, para concluir as fases do processo de incubação.

Percebe-se, portanto, a importância das incubadoras no desenvolvimento econômico da região, em função da quantidade de empreendimentos nelas abrigados. Nas incubadoras as empresas recebem um conjunto de suportes necessários à implantação, crescimento e desenvolvimento do negócio, até a liberação para atuarem de forma autônoma no mercado. 
Fabiano Maury Raupp \& Ilse Maria Beuren

\subsection{Requisitos para instalação de empreendimentos nas incubadoras}

Cumprir os requisitos necessários para a instalação de empreendimentos nas incubadoras é um dos primeiros desafios aos empreendedores que buscam no processo de incubação o suporte necessário ao crescimento do negócio. Neste contexto, é importante identificar os requisitos necessários para a instalação de empreendimentos nas incubadoras brasileiras. Na Tabela 6 apresenta-se os fatores que são analisados na seleção de empresas para incubação pelas incubadoras estudadas.

Tabela 6: Fatores analisados na seleção de empresas candidatas ao processo de incubação

\begin{tabular}{l|c|c}
\multicolumn{1}{c|}{ Fatores analisados } & \multicolumn{2}{c}{ Freqüência } \\
\cline { 2 - 3 } & N. & $\%$ \\
\hline Viabilidade do negócio & 21 & 21,43 \\
\hline Características inovadoras do produto & 12 & 12,24 \\
\hline Tecnologia do produto & 12 & 12,24 \\
\hline Perfil do empreendedor & 11 & 11,22 \\
\hline Setor de atuação do empreendimento & 8 & 8,16 \\
\hline Experiência do empreendedor no setor de atuação & 7 & 7,14 \\
\hline Geração de emprego & 6 & 6,12 \\
\hline Processo de produção não-poluente & 5 & 5,10 \\
\hline Idoneidade comercial e pessoal do proponente & 3 & 3,06 \\
\hline Importância da empresa no apoio às empresas já instaladas & 2 & 2,04 \\
\hline Possibilidade de interação com a universidade & 2 & 2,04 \\
\hline Retorno financeiro do empreendimento & 2 & 2,04 \\
\hline Outros fatores & 7 & 7,14 \\
\hline TOTAL & 98 & 100 \\
\hline
\end{tabular}

Fonte: Dados da pesquisa.

O número de indicações evidenciado é superior a amostra, uma vez que a incubadora pode considerar mais de um fator no processo de seleção. Observa-se que viabilidade do negócio é o fator com maior freqüência, apresentando $21,43 \%$ de indicação pelos respondentes. Contudo, não foi objeto deste estudo verificar quais critérios as incubadoras utilizam no processo de análise de viabilidade do negócio. Na seqüência, estão características inovadoras do produto e tecnologia do produto, ambos com 12,24\%. Seguem-se perfil do empreendedor com 11,22\%; setor de atuação do empreendimento com 8,16\%; experiência do empreendedor no setor de atuação com $6,12 \%$, e processo de produção não-poluente com $5,10 \%$. Em proporções bem menores estão os demais fatores considerados.

O item outros fatores contempla os seguintes critérios: adequação do empreendimento aos objetivos da incubadora, capacidade do empreendedor em assumir riscos, possibilidade de divulgação do nome da incubadora no produto, sinergia da equipe, compatibilidade dos recursos a serem aplicados em relação ao negócio, autonomia gerencial, equipe técnica 
Perfil do suporte oferecido pelas incubadoras brasileiras às empresas incubadas

envolvida.

Depois de analisar os fatores preconizados na fase de seleção é que as incubadoras decidem pelo ingresso ou não do empreendimento no processo de incubação. Os critérios identificados são destacados por autores abordados na fundamentação teórica, como Medeiros e Atas (1995), Aiub e Allegretti (1998) e Leite (2000). Também coadunam com o que Barrow (2001) destacou sobre os componentes de uma incubadora de sucesso.

A fase de seleção é importante não só para identificar a viabilidade do empreendimento e as capacidades do empreendedor, mas também selecionar empresas cujo suporte disponibilizado pela incubadora possa favorecê-las.

Além de questionar os coordenadores das incubadoras sobre os fatores que são analisados na seleção de empresas candidatas à incubação, arrolou-se alguns critérios para que os mesmos atribuíssem grau de importância, numa escala de 0 a 4, sendo a nota 0 (zero) para o item de menor importância e nota 4 (quatro) para o de importância máxima. A Tabela 7 apresenta a média das notas atribuídas a cada critério.

Tabela 7: Grau de importância dos critérios utilizados na seleção de empresas à incubação

\begin{tabular}{l|c}
\hline \multicolumn{1}{c}{ Critérios } & Média das notas \\
\hline Viabilidade técnica e econômica do projeto & 3,73 \\
\hline Características do(s) produto(s) da empresa & 3,55 \\
\hline Adequação do empreendimento aos objetivos da incubadora & 3,48 \\
\hline Qualificação técnica/comercial/comportamental do proponente e da equipe & 3,33 \\
\hline Exigência de processo de fabricação de produtos não-poluentes (ruído, contaminação) & 3,33 \\
\hline Retorno financeiro do novo empreendimento & 3,00 \\
\hline Controle de competitividade com outras empresas da incubadora & 2,27 \\
\hline Previsão de liberação da empresa do período de incubação & 1,97 \\
\hline
\end{tabular}

Fonte: Dados da pesquisa.

Dos critérios utilizados pelas incubadoras na seleção de empresas à incubação, os que possuem maior grau de importância, na média, são a viabilidade técnica e econômica do projeto, características do(s) produto(s) da empresa e adequação do empreendimento aos objetivos da incubadora. A qualificação técnica/comercial/comportamental do proponente e da equipe, apesar de ser um critério importante na seleção de empresas, não ocupou destaque no ranking, ficando juntamente com o item exigência de processo de fabricação de produtos não-poluentes na quarta posição.

Pode-se observar que apenas um dos critérios de seleção, previsão de liberação da empresa do período de incubação, ficou com nota média abaixo de 2. Ressalta-se ainda que, mesmo que não sejam utilizados com muita freqüência pelas incubadoras, os demais critérios possuem relevância de acordo com a opinião dos entrevistados.

Os empreendedores deverão analisar critérios específicos utilizados pelas incubadoras 
Fabiano Maury Raupp \& Ilse Maria Beuren

na seleção de empresas candidatas ao processo de incubação, a fim de verificar se esses coadunam com suas características. Cumpridos estes requisitos, o empreendimento tem a oportunidade de desenvolver-se mediante um conjunto de suportes colocados à sua disposição.

\subsection{Suporte das incubadoras brasileiras às empresas incubadas}

Os tipos de suporte que as incubadoras brasileiras oferecem às empresas incubadas foram agrupados em cinco categorias: suporte administrativo, suporte financeiro, suporte de estrutura, suporte por meio de programas desenvolvidos pelas incubadoras, e suporte por meio de programas de agentes de desenvolvimento junto às incubadoras.

\subsubsection{Suporte administrativo às empresas incubadas}

A partir do suporte administrativo, os empreendedores ampliam seus conhecimentos acerca da gestão do empreendimento em vários aspectos, que é condição essencial para a sobrevivência no mercado. A Tabela 8 apresenta a ocorrência de cada item do suporte administrativo às empresas incubadas nas diferentes fases do processo de incubação.

Tabela 8: Suporte administrativo às empresas incubadas em cada fase do processo de incubação

\begin{tabular}{|c|c|c|c|c|c|c|c|c|c|c|c|}
\hline \multicolumn{2}{|c|}{ Suporte } & \multicolumn{10}{|c|}{ Fases } \\
\hline \multirow{8}{*}{ 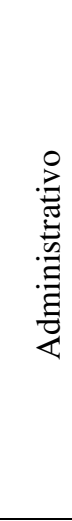 } & \multirow[t]{2}{*}{ Itens } & \multicolumn{2}{|c|}{ 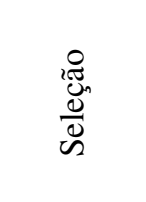 } & \multicolumn{2}{|c|}{ 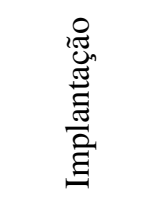 } & \multicolumn{2}{|c|}{ 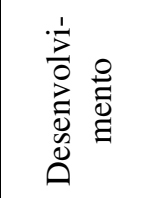 } & \multicolumn{2}{|c|}{ 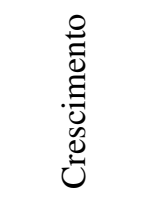 } & \multicolumn{2}{|c|}{ 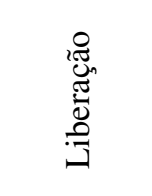 } \\
\hline & & $\mathrm{n}^{\circ}$ & $\%$ & n. ${ }^{\circ}$ & $\%$ & n. ${ }^{\circ}$ & $\%$ & n. ${ }^{\circ}$ & $\%$ & n. ${ }^{\circ}$ & $\%$ \\
\hline & Apoio jurídico & 10 & 16,13 & 21 & 15,56 & 25 & 18,38 & 26 & 17,22 & 18 & 17,65 \\
\hline & Assessoria contábil & 8 & 12,90 & 18 & 13,33 & 14 & 10,29 & 17 & 11,26 & 10 & 9,80 \\
\hline & Assessoria financeira & 9 & 14,52 & 24 & 17,78 & 23 & 16,91 & 25 & 16,56 & 15 & 14,71 \\
\hline & Assistência em marketing e gestão & 11 & 17,74 & 21 & 15,56 & 20 & 14,71 & 29 & 19,21 & 22 & 21,57 \\
\hline & Orientação empresarial e mercadológica & 12 & 19,35 & 26 & 19,26 & 28 & 20,59 & 27 & 17,88 & 21 & 20,59 \\
\hline & Serviços de secretaria & 12 & 19,35 & 25 & 18,52 & 26 & 19,12 & 27 & 17,88 & 16 & 15,69 \\
\hline TOT & & 62 & 100 & 135 & 100 & 136 & 100 & 151 & 100 & 102 & 100 \\
\hline
\end{tabular}

Fonte: Dados da pesquisa.

Barrow (2001) afirma que a disponibilização de serviços deverá considerar a fase do processo de incubação em que se encontra a empresa. Portanto, o sucesso da incubadora e das empresas incubadas será influenciado pelos tipos de serviços disponibilizados em cada fase de incubação. 
Perfil do suporte oferecido pelas incubadoras brasileiras às empresas incubadas

$\mathrm{Na}$ fase de seleção, os serviços de secretaria e orientação empresarial $e$ mercadológica foram apontados como os itens do suporte administrativo mais disponibilizados pelas incubadoras às empresas incubadas, cada um com 19,35\%. Após, com $17,74 \%$ e 16,13\%, a assistência em marketing e gestão e o apoio jurídico respectivamente. Percebe-se a importância destes itens na fase inicial de incubação, orientando os empreendedores no planejamento do negócio.

$\mathrm{Na}$ fase de implantação, aparece com maior frequiência a orientação empresarial $e$ mercadológica, com 19,26\%. Na seqüência, com 18,52\%, os serviços de secretaria e, com $17,78 \%$, a assessoria financeira. Além do planejamento do negócio, nesta fase o empreendedor começa a preocupar-se com a saúde financeira da empresa.

$\mathrm{Na}$ fase de desenvolvimento, o suporte administrativo mais disponibilizado pela incubadora às empresas incubadas é a orientação empresarial e mercadológica do empreendimento com 20,59\%. Com 19,12\% e 18,38\% de freqüência, os serviços de secretaria e o apoio jurídico respectivamente.

A fase de crescimento apresenta a assistência em marketing e gestão como o item mais oferecido pelas incubadoras aos empreendedores, com 19,21\%. Os serviços de secretaria e a orientação empresarial e mercadológica, ambos com 17,88\%, vêm na seqüência.

Na fase de liberação, onde a empresa está prestes a atuar sozinha no mercado, o item mais fornecido é a assistência em marketing e gestão com 21,57\%. A orientação empresarial e mercadológica apresenta $20,59 \%$ do total de itens do suporte administrativo disponibilizados pelas incubadoras nesta fase.

Os serviços de secretaria, a orientação empresarial e mercadológica do empreendimento e o apoio jurídico ocuparam posições de destaque em quase todas as fases do processo de incubação. A assistência em marketing e gestão também foi destaque nas diferentes fases, mas com freqüência um pouco menor.

\subsubsection{Suporte financeiro às empresas incubadas}

Essa tipologia de suporte corresponde ao apoio na captação, pagamento e aplicação dos recursos financeiros. A Tabela 9 demonstra os itens do suporte financeiro oferecidos às empresas incubadas, pelas incubadoras brasileiras, em cada fase do processo de incubação. 
Fabiano Maury Raupp \& Ilse Maria Beuren

Tabela 9: Suporte financeiro às empresas incubadas em cada fase do processo de incubação

\begin{tabular}{|c|c|c|c|c|c|c|c|c|c|c|c|}
\hline \multicolumn{2}{|r|}{ Suporte } & \multicolumn{10}{|c|}{ Fases } \\
\hline \multirow{7}{*}{ 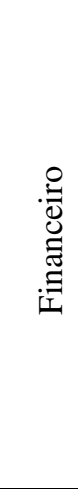 } & \multirow[t]{2}{*}{ Itens } & \multicolumn{2}{|r|}{ 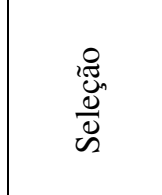 } & \multicolumn{2}{|c|}{ 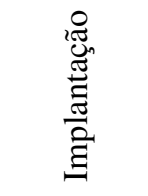 } & \multicolumn{2}{|c|}{ 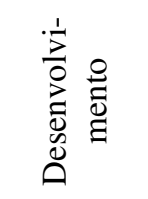 } & \multicolumn{2}{|r|}{ 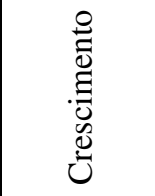 } & \multicolumn{2}{|r|}{ 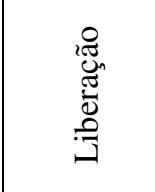 } \\
\hline & & n. ${ }^{\circ}$ & $\%$ & n. ${ }^{\circ}$ & $\%$ & n. ${ }^{\circ}$ & $\%$ & n. ${ }^{\circ}$ & $\%$ & n. ${ }^{\circ}$ & $\%$ \\
\hline & Captação de recursos & 4 & 22,22 & 18 & 27,27 & 22 & 27,50 & 22 & 25,88 & 15 & 28,85 \\
\hline & Aplicação dos recursos & 5 & 27,78 & 15 & 22,73 & 17 & 21,25 & 15 & 17,65 & 8 & 15,38 \\
\hline & Obtenção de capital de risco & 1 & 5,56 & 10 & 15,15 & 13 & 16,25 & 18 & 21,18 & 12 & 23,08 \\
\hline & Juros subsidiados & 1 & 5,56 & 5 & 7,58 & 7 & 8,75 & 7 & 8,24 & 5 & 9,62 \\
\hline & Custos compartilhados & 7 & 38,89 & 18 & 27,27 & 21 & 26,25 & 23 & 27,06 & 12 & 23,08 \\
\hline TOTA & & 18 & 100 & 66 & 100 & 80 & 100 & 85 & 100 & 52 & 100 \\
\hline
\end{tabular}

Fonte: Dados da pesquisa.

Os resultados mostram que na fase de seleção o item do suporte financeiro mais fornecido pelas incubadoras é custos compartilhados com 38,89\%. Em seguida, estão a captação de recursos e aplicação de recursos, com $27,78 \%$ e 22,22\% respectivamente.

$\mathrm{Na}$ fase de implantação, os itens mais disponibilizados, com $27,27 \%$, são custos compartilhados e captação de recursos. Na seqüência, com 22,73\% vem a aplicação de recursos.

Seguindo um comportamento semelhante ao das fases anteriores, a captação de recursos e os custos compartilhados são os itens do suporte financeiro mais disponibilizados às empresas incubadas na fase de desenvolvimento, com 27,50\% e 26,25\% respectivamente. A aplicação de recursos apresenta 21,25\%, ficando na terceira posição.

Já na fase de crescimento, o item mais destacado foi custos compartilhados com 27,06\%. Em seguida, com 25,88\% está a captação de recursos.

$\mathrm{Na}$ fase de liberação, a captação de recursos apresenta o maior percentual, com 28,85\%. Após, com 23,08\%, estão custos compartilhados e obtenção de capital de risco. Aparece no ranking dos mais fornecidos um elemento novo, o capital de risco, necessário para alavancar o empreendimento prestes a ser graduado.

Em todas as fases os itens captação de recursos e custos compartilhados ocuparam posições relevantes no ranking. Demonstra a importância destes tipos de suporte financeiro nas fases do processo de incubação que, conforme Barrow (2001), é essencial para o desenvolvimento das empresas incubadas.

\subsubsection{Suporte de estrutura às empresas incubadas}

O suporte de estrutura corresponde à estrutura física e humana que as incubadoras de 
Perfil do suporte oferecido pelas incubadoras brasileiras às empresas incubadas

empresas disponibilizam aos empreendedores incubados. Para Barrow (2001), as necessidades relacionadas ao suporte de estrutura irão variar de acordo com o foco da incubadora. A Tabela 10 apresenta a disponibilização de cada item do suporte de estrutura às empresas incubadas nas diferentes fases do processo de incubação.

Tabela 10: Suporte de estrutura às empresas incubadas em cada fase do processo de incubação

\begin{tabular}{|c|c|c|c|c|c|c|c|c|c|c|c|}
\hline & Suporte & & & & & & ases & & & & \\
\hline & Itens & & 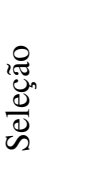 & & 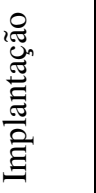 & & $\frac{\stackrel{0}{\Xi}}{\stackrel{0}{\Xi}}$ & & 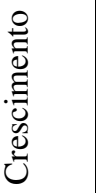 & & 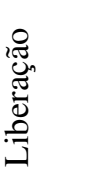 \\
\hline & & n. ${ }^{\circ}$ & $\%$ & n. ${ }^{\circ}$ & $\%$ & n. ${ }^{\circ}$ & $\%$ & n. ${ }^{\circ}$ & $\%$ & n. ${ }^{\circ}$ & $\%$ \\
\hline$\Xi$ & Módulos individuais & 5 & 5,05 & 28 & 10,73 & 26 & 10,48 & 26 & 10,08 & 17 & 9,55 \\
\hline E & Show room & 4 & 4,04 & 11 & 4,21 & 14 & 5,65 & 15 & 5,81 & 7 & 3,93 \\
\hline 0 & Recepção & 13 & 13,13 & 32 & 12,26 & 30 & 12,10 & 31 & 12,02 & 21 & 11,80 \\
\hline & Salas de reunião & 14 & 14,14 & 32 & 12,26 & 30 & 12,10 & 31 & 12,02 & 23 & 12,92 \\
\hline & Serviços de apoio & 15 & 15,15 & 31 & 11,88 & 29 & 11,69 & 30 & 11,63 & 23 & 12,92 \\
\hline & Serviços de treinamento & 16 & 16,16 & 33 & 12,64 & 30 & 12,10 & 31 & 12,02 & 24 & 13,48 \\
\hline & Serviços de comunicação & 11 & 11,11 & 28 & 10,73 & 27 & 10,89 & 30 & 11,63 & 19 & 10,67 \\
\hline & Serviços de limpeza e segurança & 10 & 10,10 & 33 & 12,64 & 31 & 12,50 & 32 & 12,40 & 22 & 12,36 \\
\hline & Sanitários e copa & 11 & 11,11 & 33 & 12,64 & 31 & 12,50 & 32 & 12,40 & 22 & 12,36 \\
\hline TOTA & & 99 & 100 & 261 & 100 & 248 & 100 & 258 & 100 & 178 & 100 \\
\hline
\end{tabular}

Fonte: Dados da pesquisa.

Verifica-se que na fase de seleção os itens do suporte de estrutura que mais são disponibilizados às empresas incubadas são os serviços de treinamento com 16,16\%, os serviços de apoio com 15,15\%, e as salas de reunião com 14,14\%. Percebe-se que os demais tipos de serviços, mesmo não fazendo parte das primeiras posições no ranking, são amplamente oferecidos aos empreendedores.

Com igual frequiência na fase de implantação, 12,64\%, foram apontados os serviços de treinamento, os serviços de limpeza e segurança, e os sanitários e copa. Seguem-se, com $12,26 \%$, os serviços de recepção e as salas de reunião.

$\mathrm{Na}$ fase de desenvolvimento, os serviços de limpeza e segurança e os sanitários $e$ copa apresentam igual frequiência de disponibilização com 12,50\%. A recepção, as salas de reunião e os serviços de treinamento foram indicados por $12,10 \%$ dos respondentes.

Esta tendência também é percebida na fase de crescimento, em que os serviços de limpeza e segurança e os serviços de sanitários e copas apresentam 12,40\% de freqüência como serviços oferecidos nesta fase. Os serviços de recepção, as salas de reunião e os serviços de treinamento denotam uma igualdade de freqüência com 12,02\%.

$\mathrm{Na}$ fase de liberação, a primeira posição é ocupada pelos serviços de treinamento com 13,48\%. As salas de reunião e os serviços de apoio apresentam cada um 12,92\% das 
Fabiano Maury Raupp \& Ilse Maria Beuren

indicações.

Infere-se do exposto que os tipos de serviços de estrutura mais disponibilizados pelas incubadoras às empresas incubadas são os mesmos em quase todas as fases do processo de incubação. Observou-se maior destaque para os itens sala de reunião e serviços de treinamento.

\subsubsection{Suporte por meio de programas desenvolvidos pelas incubadoras}

Averiguou-se, também, os tipos de programas desenvolvidos, pela incubadora e/ou por agentes de desenvolvimento junto à incubadora como forma de suporte aos incubados em cada fase do processo de incubação. A Tabela 11 mostra os programas desenvolvidos pelas incubadoras em cada fase de incubação.

Tabela 11: Programas desenvolvidos pelas incubadoras em cada fase de incubação

\begin{tabular}{|c|c|c|c|c|c|c|c|c|c|c|c|}
\hline \multicolumn{2}{|r|}{ Programas } & \multicolumn{10}{|c|}{ FASES } \\
\hline \multirow{9}{*}{ 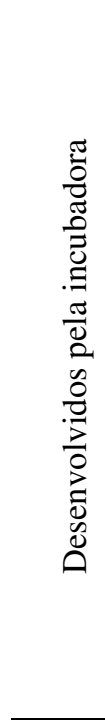 } & \multirow[t]{2}{*}{ Itens } & \multicolumn{2}{|r|}{ 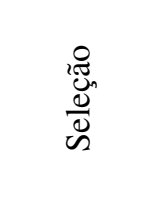 } & \multicolumn{2}{|c|}{ 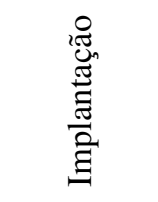 } & \multicolumn{2}{|c|}{ 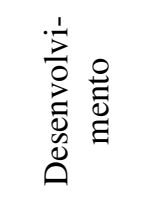 } & \multicolumn{2}{|c|}{ 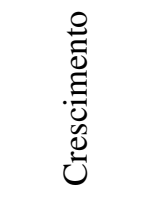 } & \multicolumn{2}{|r|}{ 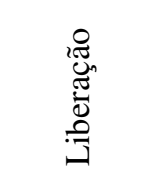 } \\
\hline & & n. ${ }^{\circ}$ & $\%$ & n. ${ }^{\circ}$ & $\%$ & n. ${ }^{\circ}$ & $\%$ & n..$^{\circ}$ & $\%$ & n. ${ }^{\circ}$ & $\%$ \\
\hline & Utilização de laboratórios & 5 & 6,49 & 20 & 13,33 & 23 & 13,77 & 20 & 12,42 & 12 & 11,21 \\
\hline & Utilização de bibliotecas e instalações & 15 & 19,48 & 30 & 20,00 & 28 & 16,77 & 19 & 11,80 & 19 & 17,76 \\
\hline & $\begin{array}{l}\text { Contratação de consultores para as } \\
\text { empresas }\end{array}$ & 12 & 15,58 & 24 & 16,00 & 27 & 16,17 & 28 & 17,39 & 18 & 16,82 \\
\hline & $\begin{array}{l}\text { Contratos de pesquisa entre universidades e } \\
\text { empresas }\end{array}$ & 6 & 7,79 & 13 & 8,67 & 20 & 11,98 & 22 & 13,66 & 10 & 9,35 \\
\hline & $\begin{array}{l}\text { Participação de pesquisadores e alunos } \\
\text { universitários nas incubadoras }\end{array}$ & 10 & 12,99 & 18 & 12,00 & 21 & 12,57 & 25 & 15,53 & 14 & 13,08 \\
\hline & Participação dos empresários em eventos & 13 & 16,88 & 25 & 16,67 & 29 & 17,37 & 30 & 18,63 & 23 & 21,50 \\
\hline & $\begin{array}{l}\text { Realização de seminários sobre o tema } \\
\text { incubadoras }\end{array}$ & 16 & 20,78 & 20 & 13,33 & 19 & 11,38 & 17 & 10,56 & 11 & 10,28 \\
\hline TOTA & & 77 & 100 & 150 & 100 & 167 & 100 & 161 & 100 & 107 & 100 \\
\hline
\end{tabular}

Fonte: Dados da pesquisa.

O número de indicações evidenciado em cada fase do processo de incubação é superior a amostra, haja vista que a incubadora pode potencializar mais de um programa em cada fase. $\mathrm{Na}$ fase de seleção os programas mais desenvolvidos pelas incubadoras brasileiras estudadas são realização de seminários sobre o tema incubadoras com 20,78\%, utilização de bibliotecas e instalações com 19,48\%, e participação dos empresários em eventos com $16,88 \%$.

Por sua vez, na fase de implantação os programas com maior freqüência de disponibilização correspondem à utilização de bibliotecas e instalações com 20,00\%, 
Perfil do suporte oferecido pelas incubadoras brasileiras às empresas incubadas

participação dos empresários em eventos com 16,67\%, e contratação de consultores para as empresas com $16,00 \%$.

A fase de desenvolvimento apresenta situação análoga a fase anterior. Os programas mais desenvolvidos são participação dos empresários em eventos com 17,37\%, utilização de bibliotecas e instalações com 16,77\%, e contratação de consultores para as empresas com $16,17 \%$.

Na fase de crescimento, a participação dos empresários em eventos ocupa a primeira posição no ranking dos programas desenvolvidos, com 18,63\%. Em seguida, aparece a contratação de consultores para as empresas com 17,39\%, e, com 15,53\%, participação de pesquisadores e alunos universitários nas incubadoras.

A fase de liberação contempla a participação dos empresários em eventos como o programa mais desenvolvido, com freqüência de 21,50\%. Na seqüência, os programas que apresentam maior freqüência são utilização de bibliotecas e instalações com 17,76\%, e contratação de consultores para as empresas com 16,82\%.

Entre os programas desenvolvidos pelas incubadoras brasileiras pesquisadas, a participação dos empresários em eventos, a utilização de bibliotecas e instalações e a contratação de consultores para as empresas, ocuparam posições relevantes em quase todas as fases do processo de incubação.

\subsubsection{Programas desenvolvidos por agentes de desenvolvimento junto às incubadoras}

Assim como se procedeu com os programas das incubadoras, verificou-se os programas desenvolvidos por agentes de desenvolvimento junto às incubadoras em cada fase do processo de incubação. A tabulação dos dados relacionados a esta questão é evidenciada na Tabela 12. 
Fabiano Maury Raupp \& Ilse Maria Beuren

Tabela 12: Programas de agentes de desenvolvimento junto às incubadoras em cada fase de incubação

\begin{tabular}{|c|c|c|c|c|c|c|c|c|c|c|c|}
\hline \multicolumn{2}{|r|}{ Programas } & \multicolumn{10}{|c|}{ Fases } \\
\hline 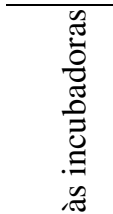 & \multirow[t]{2}{*}{ Itens } & \multicolumn{2}{|r|}{ 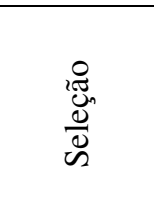 } & \multicolumn{2}{|c|}{ 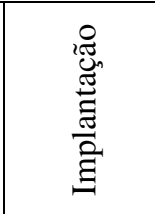 } & \multicolumn{2}{|c|}{ 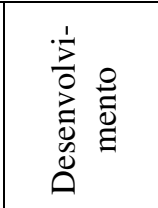 } & \multicolumn{2}{|r|}{ 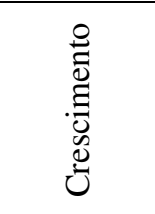 } & \multicolumn{2}{|r|}{ 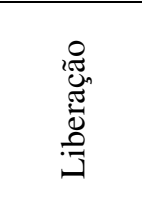 } \\
\hline$\stackrel{0}{=}$ & & n. ${ }^{\circ}$ & $\%$ & n. ${ }^{\circ}$ & $\%$ & $\mathrm{n}^{\mathrm{o}}$ & $\%$ & n. ${ }^{\circ}$ & $\%$ & n. ${ }^{\circ}$ & $\%$ \\
\hline$\stackrel{\Xi}{\stackrel{\Xi}{0}}$ & $\begin{array}{l}\text { Programa Nacional de Apoio à Incubadoras } \\
\text { de Empresas }\end{array}$ & 7 & 16,28 & 17 & 14,91 & 19 & 15,45 & 19 & 16,10 & 12 & 15,38 \\
\hline$\Xi$ & Projeto Inovar & 6 & 13,95 & 10 & 8,77 & 11 & 8,94 & 12 & 10,17 & 10 & 12,82 \\
\hline$\frac{1}{2}$ & $\begin{array}{l}\text { Programa de Capacitação de Recursos } \\
\text { Humanos para Atividades Estratégicas }\end{array}$ & 4 & 9,30 & 10 & 8,77 & 17 & 13,82 & 14 & 11,86 & 8 & 10,26 \\
\hline$\overline{0}$ & Programa SOFTEX & 6 & 13,95 & 9 & 7,89 & 10 & 8,13 & 8 & 6,78 & 7 & 8,97 \\
\hline 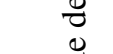 & SEBRAEtec & 5 & 11,63 & 18 & 15,79 & 22 & 17,89 & 19 & 16,10 & 14 & 17,95 \\
\hline 营 & $\begin{array}{l}\text { Programa de Apoio Tecnológico às Micro e } \\
\text { Pequenas Empresas }\end{array}$ & 4 & 9,30 & 20 & 17,54 & 19 & 15,45 & 19 & 16,10 & 11 & 14,10 \\
\hline 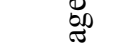 & Programa de Capacitação Tecnológica & 4 & 9,30 & 20 & 17,54 & 16 & 13,01 & 16 & 13,56 & 10 & 12,82 \\
\hline อั & Programa Brasil Empreendedor & 7 & 16,28 & 10 & 8,77 & 9 & 7,32 & 11 & 9,32 & 6 & 7,69 \\
\hline TOTAL & & 43 & 100 & 114 & 100 & 123 & 100 & 118 & 100 & 78 & 100 \\
\hline
\end{tabular}

Fonte: Dados da pesquisa.

Infere-se que o número de indicações em cada fase do processo de incubação é superior a amostra, uma vez que a incubadora pode potencializar mais de um programa em cada fase. Observa-se que dos programas desenvolvidos por agentes de desenvolvimento junto às incubadoras, na fase de seleção, a primeira posição é ocupada pelo Programa Brasil Empreendedor e pelo Programa Nacional de Apoio à Incubadoras de Empresas, cada um com 16,28\%. Na seqüência, o Projeto Inovar e o Programa SOFTEX apresentam igual freqüência de $13,95 \%$.

$\mathrm{Na}$ fase de implantação, verifica-se que os programas com maior freqüência são o Programa de Capacitação Tecnológica e o Programa de Apoio Tecnológico às Micro e Pequenas Empresas, cada um com 17,54\%. Na seqüência, está o programa SEBRAEtec com $15,79 \%$.

Nota-se que na fase de desenvolvimento o programa SEBRAEtec é o mais disponibilizado pelas incubadoras com 17,89\%. O Programa Nacional de Apoio à Incubadoras de Empresas e o Programa de Apoio Tecnológico às Micro e Pequenas Empresas apresentam, cada um, 15,45\%.

Verifica-se que na fase de crescimento, o Programa Nacional de Apoio à Incubadoras de Empresas, o SEBRAEtec e o Programa de Apoio Tecnológico às Micro e Pequenas Empresas mostram as maiores frequiências, com 16,10\% cada um, seguido pelo Programa de Capacitação Tecnológica com 13,56\%.

$\mathrm{Na}$ fase de liberação, o programa mais disponibilizado é o SEBRAEtec com 17,95\%, 
Perfil do suporte oferecido pelas incubadoras brasileiras às empresas incubadas

seguido pelo Programa Nacional de Apoio à Incubadoras de Empresas com 15,38\% de disponibilização. O Projeto Inovar e o Programa de Capacitação Tecnológica representam, cada um, $12,82 \%$ dos programas desenvolvidos por agentes de desenvolvimento nesta fase.

$\mathrm{O}$ programa mais disponibilizado por agentes de desenvolvimento junto às incubadoras é o Programa Nacional de Apoio à Incubadoras de Empresas. O SEBRAEtec, o Programa de Apoio Tecnológico às Micro e Pequenas Empresas e o Programa de Capacitação Tecnológica também ocupam posições de destaque nas diferentes fases do processo de incubação.

\section{CONCLUSÕES E RECOMENDAÇÕES}

As incubadoras de empresas passaram a constituir um reduto de idéias, com intuito de concretizá-las a partir de auxílio no desenvolvimento de empresas, especialmente as micro e pequenas empresas. Em sentido amplo, as incubadoras podem ser consideradas organizações que envolvem um complexo sistema, denominado processo de incubação, cujas inter-relações entre seus subsistemas criam sinergia entre eles, promovendo o crescimento da empresa incubada. Em sentido restrito, as incubadoras podem ser visualizadas como um mecanismo que possibilita crescimento estável de micro e pequenas empresas, através da disponibilização de um conjunto de suportes.

Por tratar-se de um estudo descritivo, além de concluir sobre o fenômeno investigado, fez-se inferências a partir da análise dos dados coletados nas incubadoras pesquisadas, contribuindo para futuros estudos que tenham como temática os tipos de suportes disponibilizados nas incubadoras de empresas que, segundo Rice e Mattews (1995), compreendem fatores críticos de sucesso para as incubadoras.

Observou-se que os critérios mais utilizados pelas incubadoras brasileiras no recrutamento e seleção de empresas são viabilidade do negócio, característica inovadora do produto, tecnologia do produto, perfil empreendedor, setor de atuação do empreendimento, experiência do empreendedor no setor em que pretende atuar, e processo de produção não poluente. Alguns destes critérios obtiveram elevados graus de importância, na média, por meio de notas atribuídas pelos respondentes. $\mathrm{O}$ empreendedor que deseja ingressar em alguma incubadora brasileira deverá considerar, juntamente aos critérios mencionados, critérios específicos que algumas incubadoras utilizam na seleção de empreendimentos.

Os critérios identificados pelos respondentes da pesquisa encontram-se respaldados nas concepções de autores abordados na fundamentação teórica, como Medeiros e Atas 
(1995), Aiub e Allegretti (1998) e Leite (2000), que mencionam os principais critérios adotados no Brasil para seleção de empresas candidatas a ocupar uma vaga na incubadora. Também coadunam com experiências internacionais, como a preconizada por Barrow (2001).

Verificou-se que os suportes administrativos mais disponibilizados pelas incubadoras às empresas incubadas, nas diferentes fases, são apoio jurídico, orientação empresarial e mercadológica e serviços de secretaria. Já os suportes financeiros que mais se destacaram foram apoio na captação de recursos e custos compartilhados durante o processo de incubação. Quanto aos serviços de estrutura, os mais disponibilizados são os serviços de treinamento e a utilização de salas de reunião. Os números de cada categoria de suporte disponibilizada são bastante próximos entre as diferentes fases do processo de incubação.

A estrutura de categorias de suporte utilizada neste estudo para agrupar os serviços disponibilizados pelas incubadoras às empresas incubadas, difere da categorização apresentada por Medeiros (1998). No entanto, os itens de suportes averiguados a partir da tabulação dos dados da pesquisa coadunam com os destacados por Medeiros e Atlas (1995), Medeiros (1998) e Baêta (1999), como os serviços oferecidos pelas incubadoras brasileiras às empresas incubadas. Além disso, estão de acordo com os componentes de sucesso de uma incubadora destacados por Barrow (2001).

Dentre o conjunto de programas desenvolvidos pelas incubadoras, aqueles que mais se destacaram, nas diversas fases de incubação, foram utilização de bibliotecas e instalações e participação dos empresários em eventos. No que concerne aos programas de agentes de desenvolvimento junto às incubadoras, os mais disponibilizados, nas várias fases, são o Programa Nacional de Apoio à Incubadoras de Empresas e o SEBRAEtec.

Os programas desenvolvidos pelas incubadoras brasileiras pesquisadas estão de acordo com os preconizados por Baêta (1999) e Leite (2000). Os programas de agentes de desenvolvimento junto às incubadoras vistos na revisão bibliográfica também foram indicados pelos respondentes da pesquisa.

O presente estudo não pode abordar todos os aspectos relacionados ao suporte das incubadoras às empresas incubadas. Todavia, ao longo da pesquisa foram identificadas outras temáticas que poderão ser estudadas em futuras pesquisas.

Os principais tópicos identificados como recomendações são os seguintes: reaplicar a pesquisa junto aos empreendedores incubados considerando as respostas dos coordenadores das incubadoras obtidas na presente pesquisa; comparar o suporte oferecido por incubadoras brasileiras com o suporte oferecido por incubadoras de outros países; relacionar o suporte oferecido com o grau de desenvolvimento econômico da região. 
Perfil do suporte oferecido pelas incubadoras brasileiras às empresas incubadas

\section{REFERÊNCIAS}

AIUB, George Wilson; ALLEGRETTI, Rogério Della Fávera. Planejamento: orientação estratégica para análise de viabilidade e estruturação de incubadoras de empresas. Porto Alegre: SEBRAE, 1998.

AMATO NETO, João. Redes de cooperação produtiva e clusters regionais: oportunidades para as pequenas e médias empresas. São Paulo: Atlas e Fundação Vanzolini, 2000.

ASSOCIAÇÃO NACIONAL DE ENTIDADES PROMOTORAS DE EMPREENDIMENTOS DE TECNOLOGIAS AVANÇADAS - ANPROTEC. Incubadora de empresas. Disponível em: $<$ http://www.anprotec.org.br/anprotec.htm\#5 >. Acesso em: $10 \mathrm{dez} .2008$.

BAÊTA, Adelaide Maria Coelho. O desafio da criação: uma análise das incubadoras de empresas de base tecnológica. Petrópolis: Vozes, 1999.

BARROW, Colin. Incubators: a realist's guide to the world's new business accelerators. Chichester; New York: John Wiley \& Sons, 2001.

CONTANDRIOPOULOS, André-Pierre et al. Saber preparar uma pesquisa: definição, estrutura e financiamento. São Paulo: Hucitec: Abrasco, 1994.

DORNELAS, José Carlos Assis. Empreendedorismo: transformando idéias em negócios. Rio de Janeiro: Campus, 2001.

FONSECA, Sérgio Azevedo; KRUGLIANSKAS, Isak. Avaliação do desempenho de incubadoras empresariais mistas: um estudo de caso no Estado de São Paulo, Brasil. In: IASP - CONFERÊNCIA LATINOAMERICANA DE PARQUES TECNOLÓGICOS E INCUBADORAS DE EMPRESAS, 2000, Panamá. Anais... Panamá: IASP, 2000. CD ROM.

GIL, A. C. Métodos e técnicas de pesquisa social. São Paulo: Atlas, 1999.

HACKETT, S. M.; DILTS, D. M. A systematic review of business incubation research. Journal of Technology Transfer, Indianapolis, v. 29, n. 1, p. 55-82, 2004.

LALKAKA, Rustam. Business Incubator in developping countries: characteristics and performance. International Journal of Entrepreneurship and Innovation Management, v. 3, 2003.

LEITE, Emanuel. O fenômeno do empreendedorismo. Recife: Bagaço, 2000.

MARTINS, Gilberto de Andrade. Manual para elaboração de monografias e dissertações. São Paulo: Atlas, 2000.

MEDEIROS, José Adelino; ATAS, Lucília. Incubadoras de empresas: balanço da experiência brasileira. Revista de Administração da USP, São Paulo, v. 30, n. 1, p. 19-31, jan./mar., 1995. 
MEDEIROS, José Adelino. Incubadoras de empresas: lições da experiência internacional. Revista de Administração da USP, São Paulo, v. 33, n. 2, abr./jun., p. 5-20, 1998.

MOREIRA, José Henrique. Modelo de gestão para incubação de empresas orientado a capital de risco. 2002. 131f. Dissertação (Mestrado em Engenharia de Produção) - Programa de Pós-Graduação em Engenharia de Produção, Universidade Federal de Santa Catarina, Florianópolis, 2002.

NATIONAL BUSINESS INCUBATION ASSOCIATION - NBIA. What is business incubation? Disponível em: <http://www.nbia.org >. Acessado em: 08 dez. 2008.

RICE, M. P.; MATTEWS, J. B. Growing new ventures: creating new jobs. Westport: Quorum Books, 1995.

RICHARDSON, Roberto Jarry. Pesquisa social: métodos e técnicas. São Paulo: Atlas, 1999. RUSSI JUNIOR, Alberto. Metodologia para avaliação e seleção de projetos de empreendimentos de base tecnológica: com enfoque em incubadoras de empresas. 1999.

118f. Dissertação (Mestrado em Engenharia de Produção) - Programa de Pós-Graduação em Engenharia de Produção, Universidade Federal de Santa Catarina, Florianópolis, 1999.

TRIPODI, Tony; FELLIN, Phillip; MEYER, Henry. Análise da pesquisa social. 2. ed. Rio de Janeiro: F. Alves, 1981.

\title{
RESUMO
}

$\mathrm{O}$ artigo objetiva delinear o perfil do suporte oferecido pelas incubadoras brasileiras às empresas incubadas. Trata-se de um estudo descritivo, de natureza quanti-qualitativa, realizado por meio de pesquisa survey. A população da pesquisa corresponde a 179 incubadoras brasileiras, tendo-se obtido um retorno de 37 delas. A coleta de dados deu-se com base em questionário enviado por e-mail aos coordenadores das incubadoras. Inicia-se o estudo fazendo uma breve incursão teórica acerca de incubadoras de empresas, fases do processo de incubação e suporte das incubadoras às empresas incubadas. Na seqüência, identifica-se os procedimentos metodológicos adotados. Em seguida, procede-se à descrição e análise dos dados coletados. Por último, apresenta-se as conclusões do estudo realizado, bem como recomendações para futuras pesquisas.

Palavras-chave: Suporte; Incubadoras Brasileiras; Empresas Incubadas; Processo de Incubação.

\section{THE PROFILE OF THE SUPPORT OFFERED BY THE BRAZILIAN INCUBATORS TO THE INCUBATED COMPANIES}

\begin{abstract}
The goal of this article is to outline the profile of the support offered by the Brazilian incubators to the incubated companies. This is a descriptive study, based on both quality and quantity, done through a survey. The target of the research was 179 Brazilian incubators, having heard from 37 of them. The data collection was based on questionnaire sent through e-mail to the coordinators of the incubators. The study began with a brief theoretical foray about incubators of companies. After that, the adopted methodological procedures are identified. Then, the description and the analysis of the data collected are done. At last, the conclusion of the study and recommendation for future researches are presented.
\end{abstract} Key words: Support; Brazilian Incubators; Incubated Companies; Incubating Process. 